\title{
Perbaikan sarana dan prasarana Belajar Mengajar dan Pelatihan Instalasi alat-alat Listrik Rumah Tangga di Madrasah Ibtidaiyah Mibtahul Ulum, Desa Leuwi karet, Kecamatan Klapa Nunggal Kabupaten Bogor
}

\author{
Indra. $Z^{1}$, Sila Wardono ${ }^{2}$, Wisnu Hendri Mulyadi ${ }^{3}$ \\ 1,2,3 Staff Pengajar Jurusan Teknik Elektro, Politeknik Negeri Jakarta \\ Jalan. Prof. DR.G.A Siwabessy, Kampus Universitas Indonesia Depok \\ 1indra_pnj@yahoo.com, ${ }^{2}$ silawardono@yahoo.com, ${ }^{3}$ mulyadiwisnu@yahoo.co.id
}

\begin{abstract}
Abstrak
Kegiatan Pengabdian Kepada masyarakat ini mempunyai tujuan untuk perbaikan sarana dan prasarana kegiatan belajar mengajar siswa, diantaranya pembuatan Toilet / MCK untuk keperluan sanitasi guru dan murid untuk sarana berwudhu bagi guru dan siswa yang beragama muslim, serta perbaikan plafon dan kasau ruang kelas yang sudah rapuh dan bocor, di Madrasah Ibtidaiyah Miftahul Ulum Desa leuwi karet, kecamatan klapanunggal Kabupaten Bogor. Manfaat yang lebih luas adalah siswa/i, Madrasah Ibtidaiyah Miftahul Ulum dapat merasa kenyamanan di dalam ruangan kelas karena ruangan yang bersih dan kondisi toilet / MCK yang bersih dan memadai sehingga produktivitas belajar mengajar akan lebih baik.

Selain itu, kegiatan yang dilakukan adalah memberikan pelatihan dan pengarahan kepada karyawan, staf pengajar dan masyarakat sekitar, di Madrasah Ibtidaiyah Miftahul Ulum, yang materinya berisikan perawatan dan perbaikan alat alat rumah tangga seperti setrika, dispenser dan kulkas. Kegiatan ini dimaksudkan untuk memberikan pengetahuan dan kemampuan karyawan dan staf pengajar serta masyarakat sekitar, sehingga karyawan, staf pengajar dan masyarakat sekitar dapat menerapkan gerakan penghematan listrik dalam penggunaan alat alat listrik rumah tangga, dan memahami keselamatan terhadap pemakaian listrik rumah tinggal, agar terhindar dari bahaya kebakaran dan kecelakaan akibat sengatan listrik, yang nantinya dapat menerapkan serta meningkatkan pengetahuan pada proses belajar mengajar siswa.
\end{abstract}

Kata Kunci : Pengabdian, Sarana prasarana, Instalasi Listrik, , Sengatan listrik

\section{PENDAHULUAN}

kontinitas Sarana dan prasarana yang memadai dalam kegiatan belajar mengajar memegang peranan penting dalam keberhasilan proses belajar mengajar . Dengan sarana dan prasarana yang baik akan menunjang kegiatan proses belajar mengajar yang efektif, akan melindungi bangunan dan alat apabila terjadi gangguan yang tidak di inginkan. Sarana dan prasarana yang tidak memadai akan mengakibatkan kegiatan belajar mengajar tidak efektif dan siswa kekurangan gairah dalam belajar.

Perkembangan aktifitas kegiatan dan peralatan sarana dan prasarana pendukung aktivitas belajar mengajar yang meningkat, menjadi suatu hal yang harus dipenuhi, terutama sarana ruang kelas yang nyaman dan memadai terutama dalam dunia pendidikan formal seperti di lingkungan Madrasah 
Ibtidaiyah. Salah satu langkah yang dilakukan adalah dengan meningkatkan kualitas Madrasah Ibtidaiyah yang dapat dilakukan oleh banyak pihak, salah satunya oleh civitas akademik di Perguruan Tinggi.

Untuk mencari solusi dari permasalahan diatas, maka diadakanlah kegiatan program Pengabdian Masyarakat berbasis Prodi Teknik Listrik berupa "Perbaikan sarana dan prasarana Belajar Mengajar dan Pelatihan Instalasi alat-alat Listrik Rumah Tangga di Madrasah Ibtidaiyah Mibtahul Ulum, Desa Leuwi karet, Kecamatan Klapa Nunggal Kabupaten Bogor" yang merupakan respon para dosen untuk membantu menyelesaikan permasalahan yang ada.

Kegiatan ini bertujuan untuk meningkatkan sarana dan prasarana belajar mengajar terutama ruang kelas siswa seperti perbaikan perbaikan plafon ruang kelas perbaikan toilet/MCK guru dan siswa, pemasangan instalasi listrik ruang toilet/MCK dan administrasi dan guru pada madrasah Ibtidaiyah. Manfaat yang lebih luas adalah siswa di Madrasah Ibtidaiyah Mibtahul Ulum, Desa Leuwi karet, Kecamatan Klapa Nunggal Kabupaten Bogor dapat meningkatkan kualitas belajar mengajar di Madrasah Ibtidaiyah Mibtahul Ulum.

\section{Tinjauan pustaka}

Madrasah Ibtidaiyah Miftahul Ulum memiliki 149 siswa dari berbagai kalangan. Kelas 6 terdiri dari kelas 1 dengan jumlah siswa 22 anak, kelas 2 jumlah siswa 20 anak, kelas 3 jumlah siswa 23 anak, kelas 4 jumlah siswa 28 anak, kelas 5 jumlah siswa 27 anak, kelas 6 jumlah siswa 29 anak, dan hanya memiliki 5 ruang kelas, Fasilitas sekolah yang diberikan sangatlah minim dilihat dari ruang kelas yang luasnya tidak sebanding dengan jumlah siswa, kondisi papan tulis / white board tidak memadai sangat kotor dan sudah terkelupas pada bagian teriplex, ditambah lagi plafon, pintu ruangan pada rusak, dan genteng banyak yang bocor,dan ruang tidak sebanding dengan jumlah siswa yang belajar di ruang kelas.

Sekolah merupakan lembaga sosial yang keberadaannya merupakan bagian dari sistem sosial bangsa yang bertujuan untuk mencetak manusia susila yang cakap, demokratis, bertanggung jawab, beriman, bertaqwa, sehat jasmani dan rohani, memiliki pengetahuan dan keterampilan, berkepribadian yang mantap dan mandiri, agar tujuan tersebut dapat tercapai maka dibutuhkan kurikulum yang kuat, baik secara infrastruktur maupun suprastruktur. Guru sebagai pendidik dituntut untuk dapat menyelenggarakan pembelajaran yang menarik dan bermakna sehingga prestasi yang dicapai dapat sesuai dengan target yang telah ditetapkan.

Pelaksanaan pengabdian masyarakat berbasis program studi Teknik listrik, di Madrasah Ibtidaiyah Mibtahul Ulum, Desa Leuwi karet, Kecamatan Klapa Nunggal Kabupaten Bogor, berdasarkan rekomendasi dari staf pengajar prodi teknik listrik, berikut merupakan peta lokasi madrasah 


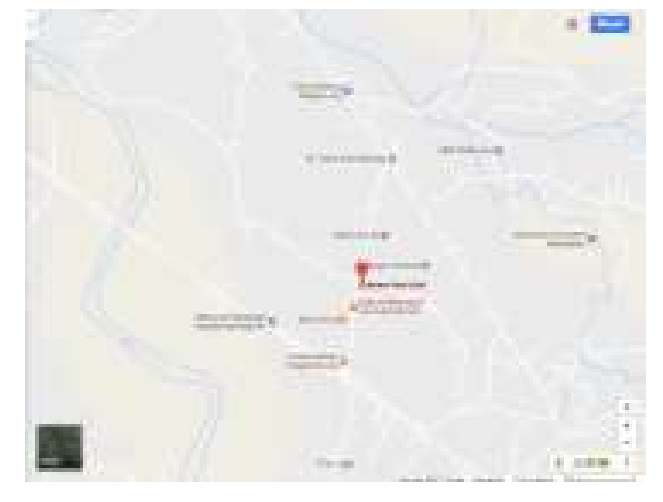

Gambar 1 peta lokasi MTs. Darul Muslim

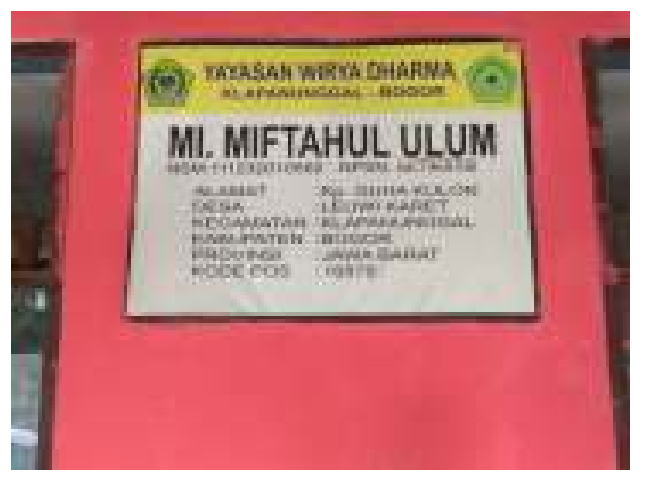

Gambar plang MTs Darul Muslim

dari informasi yang diterima, tim melakukan survey terhadap lokasi pengabdian masyarakat di Madrasah Ibtidaiyah Mibtahul Ulum, Desa Leuwi karet, Kecamatan Klapa Nunggal Kabupaten Bogor.

\section{METODE PELAKSANAAN PENGABDIAN}

Hasil kajian yang dilakukan tim pengusul dan melihat langsung dilapangan telah merekomendasikan untuk melakukan perbaikan sarana dan prasarana di Madrasah Ibtidaiyah Miftahul Ulum dan pelatihan instalasi listrik dasar dan tips dalam menghemat listrik . Berikut ini adalah rancangan kegiatan penerapan Ipteks bagi Masyarakat, diantaranya :

1. Membangun toilet / MCK untuk siswa dan guru secara total termasuk alat sanitasi, penggantian keramik dan keran untuk berwudhu siswa dan guru.

2. Penggantian pintu dan kusen Toilet kamar mandi.

3. Pengecatan bagian interior toilet dan pemasangan plafon atap toilet ruang guru dan siswa

4. Menginstalasi ruang Toilet siswa dan guru dengan yang baru dengan kelengkapan kotak kontak dan fitting lampu.

5. Mengganti kasi atap ruang kelas siswa dan mengganti plafon atap ruang siswa dengan GRC yang baru dan mengecat plafon ruang kelas.

6. Memperbaiki dinding ruang kelas yang banyak terkelupas dan melakukan pengecatan dinding kelas.

7. Memberikan pelatihan bagaimana menggunakan melakukan perawatan dan perbaikan alat alat rumah tangga, serta memberikan edukasi untuk program penghematan energi listrik dangan memberikan trik dalam menghemat penggunaan energi listrik.

\section{Kondisi Sasaran Pengabdian}

Sarana dan prasarana kegiatan belajar mengajar di Madrasah Ibtidaiyah Miftahul Ulum Desa Leuwikaret, Kecamatan Klapanunggal Kabupaten Bogor saat ini masih minim, dikarenakan keterbatasan anggaran biaya madrasah dan minimnya bantuan 
pemerintah dalam pemenuhan sarana dan prasarana. Disamping itu, minat animo masyarakat untuk menyekolahkan anaknya di daerah sekitar meningkat pesat, Hal ini tidak sebanding dengan sarana dan prasarana yang ada di madrasah.

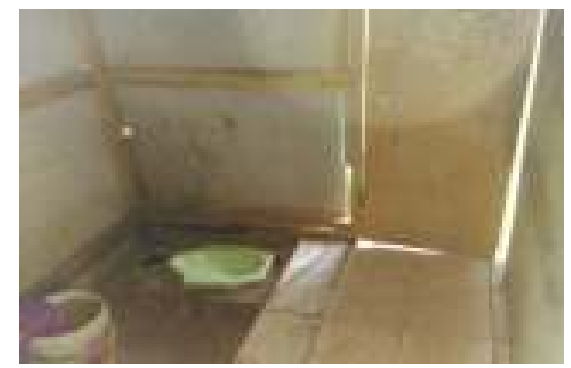

Gambar 3.1 Kondisi WC,Guru

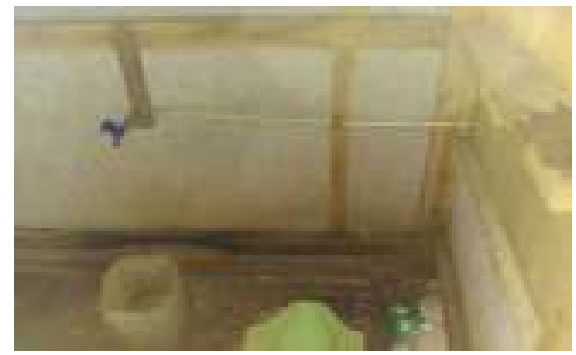

Gambar 3.2 Kondisi WC, Siswa

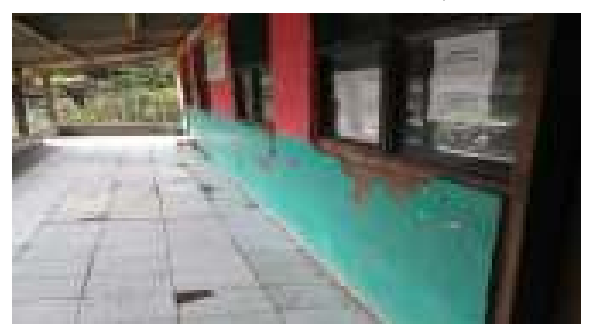

Gambar 3.3 Kondisi Dinding kelas.

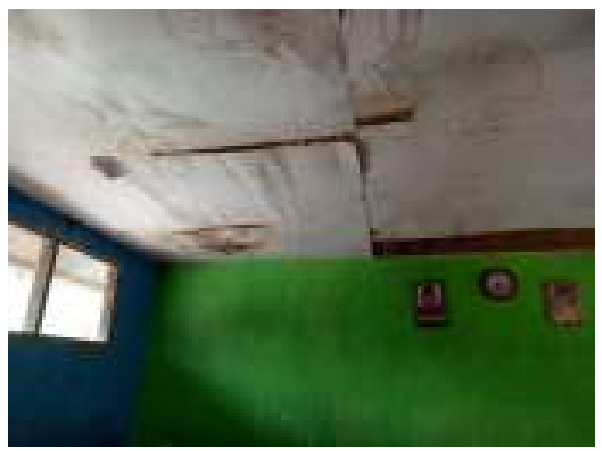

Gambar 3.4 Kondisi Flavon Kelas.

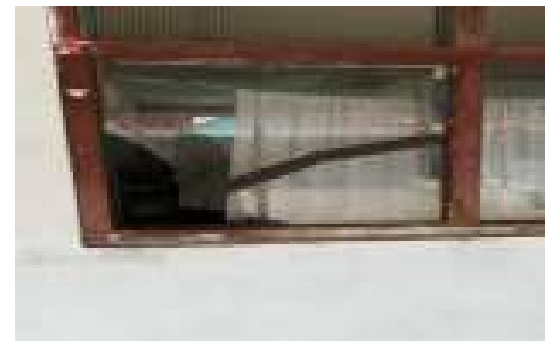

Gambar 5. Kondisi Kaca Ruang Kelas.

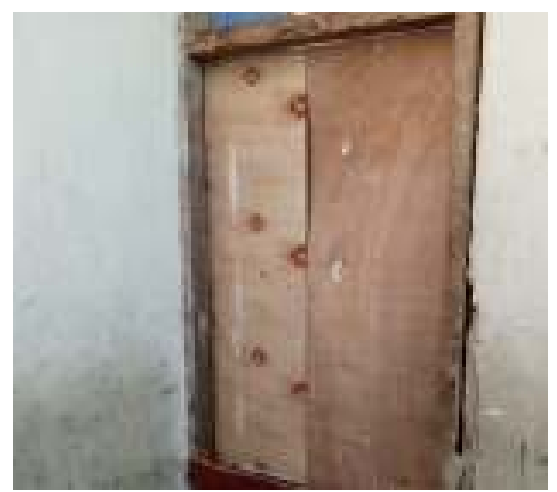

Gambar 3.6 Kondisi Pintu Toilet

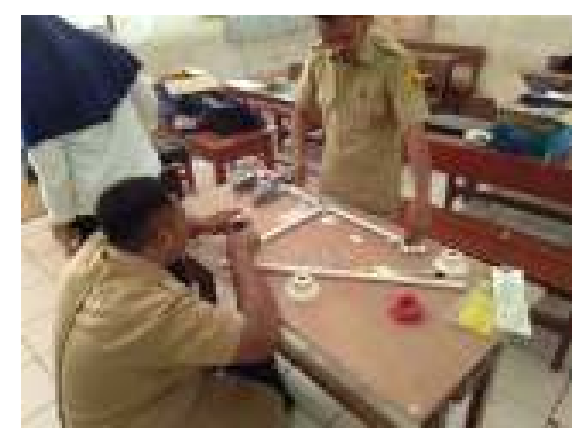

Gambar 3.6 Pemberian Pelatihan

\section{PELAKSANAAN DAN HASIL KEGIATAN PENGABDIAN}

Sebelum dilasanakan kegiatan pengabdian masyarakat didahului dengan pembukaan acara dan sambutan sambutan dari ketua jurusan Teknik Elektro, dari kepala program studi Teknik Listrik dan dari kepala sekolah madrasah Ibtidaiyah Miftahul Ulum bapak dedi dan ditutup dengan doa seperti terlihat pada gambar : 


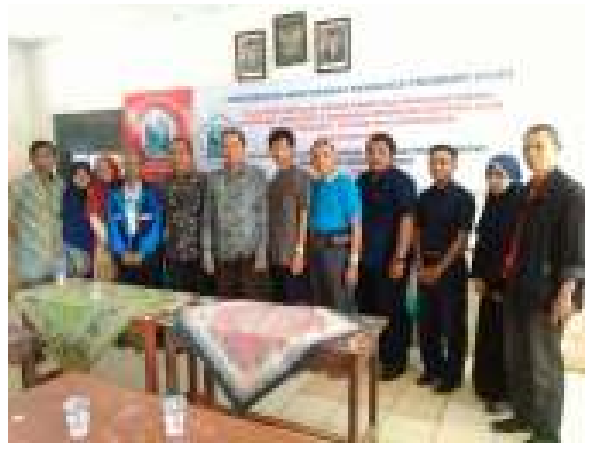

Gambar 4.1 Foto pembukaan pengabdian masyarakat desa tarikolot

Kegiatan pengabdian masyarakat dilakukan dengan melibatkan dosen, tenaga laboran dan mahasiswa, keterlibatan mahasiswa diharapkan agar mahasiswa dapat menerapkan ilmu yang telah didapat untuk diaplikasikan pada pengabdian ini terutama pengetahuan mengenai instalasi listrik domestik yang telah didapat pada matakuliah teori instalasi listrik domestik dan praktik instalasi domestik.

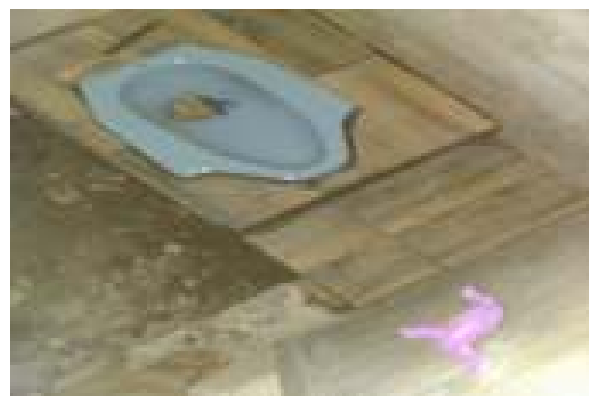

Gambar 4.1 Pekerjaa WC,

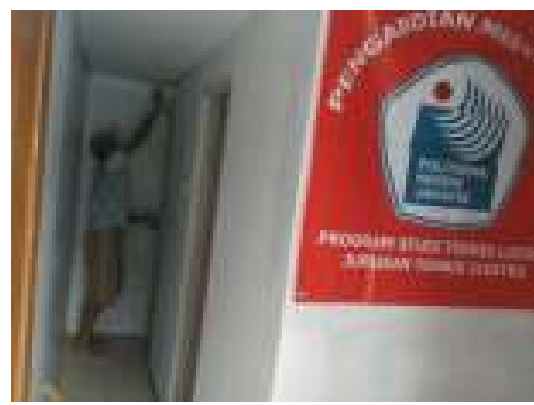

Gambar 4.2 Pekerjaan WC, Selesai

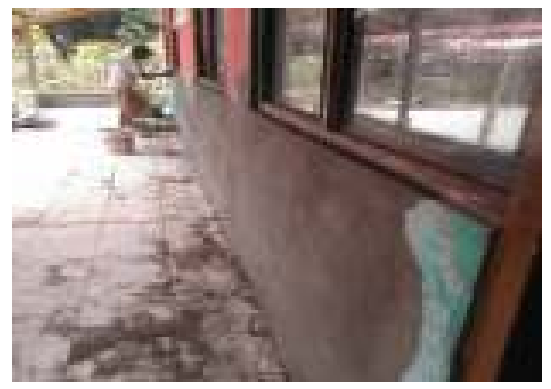

Gambar 4.3 Pekerjaan Dinding kelas

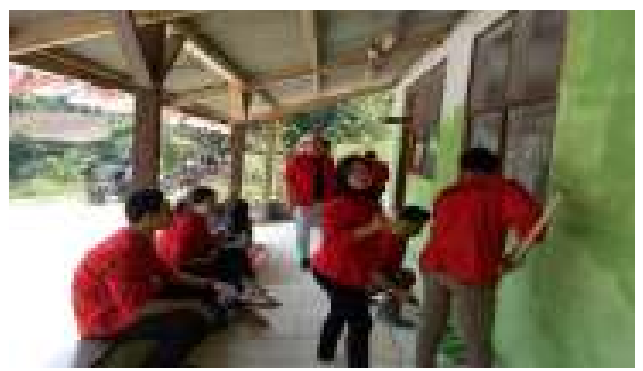

Gambar 4.4 Pekerjaan Dinding kelas

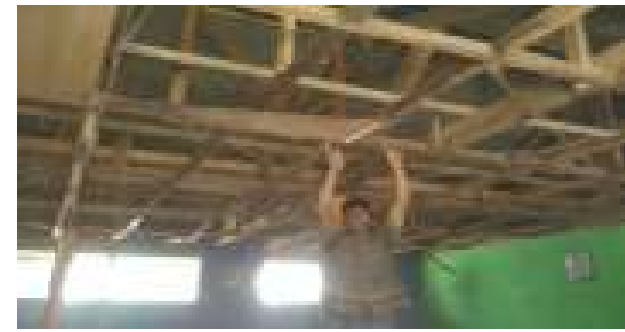

Gambar 4.5 Pekerjaan Plafon kelas
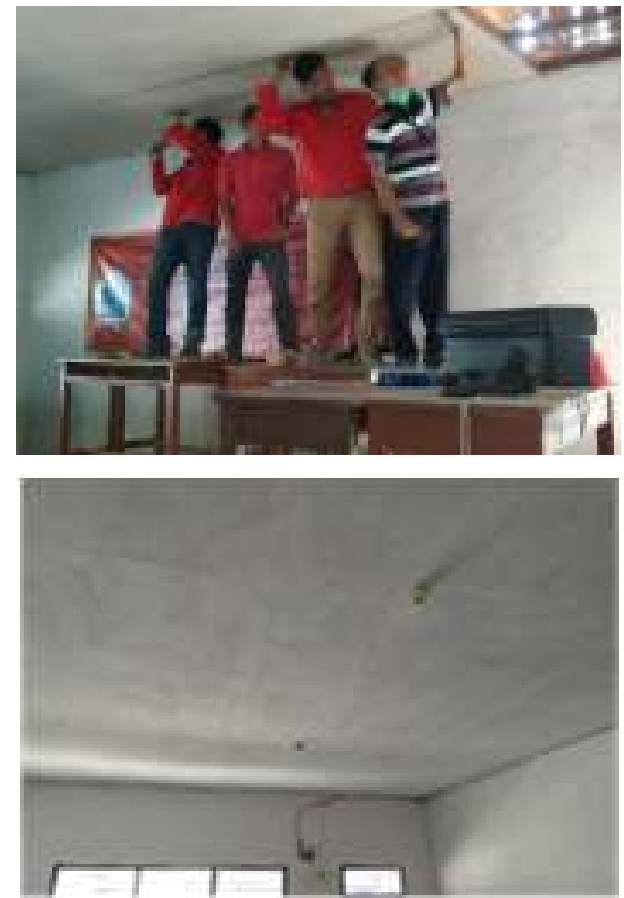
Gambar 4.6 Pekerjaan Plafon Selesai

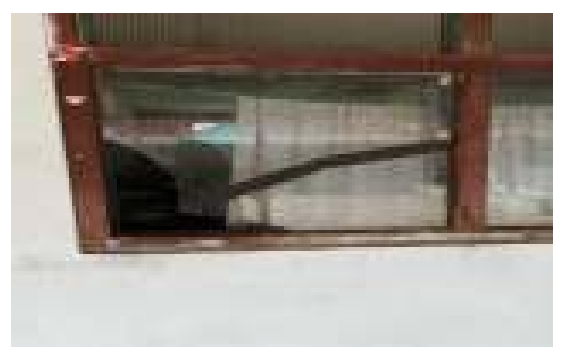

Gambar 4.7. Kondisi Kaca Ruang Kelas.

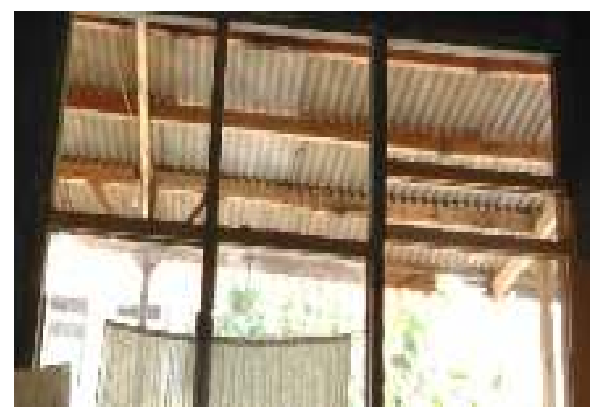

Gambar 4.8. Pengantian Kaca Ruang Kelas.

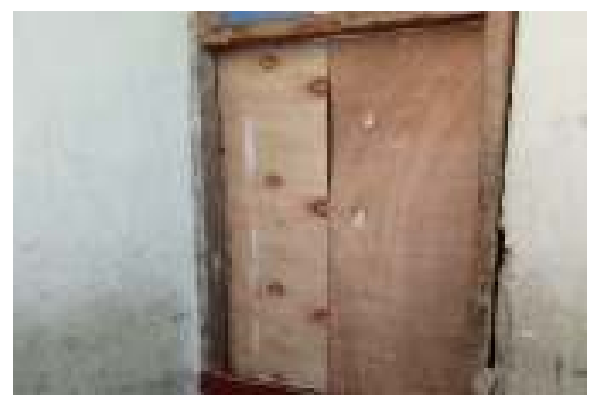

Gambar 4.9 Kondisi Pintu Toilet

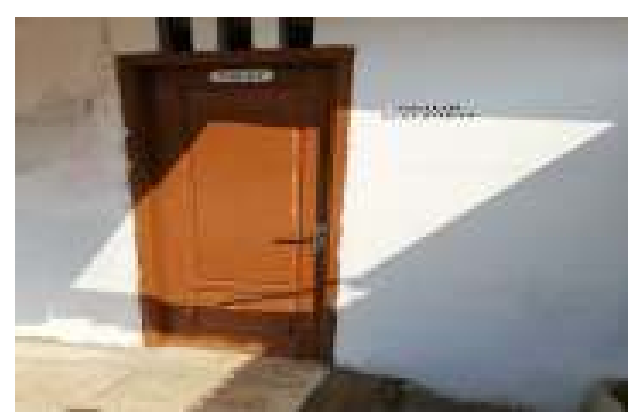

Gambar 4.10 Pintu Toilet Selesai

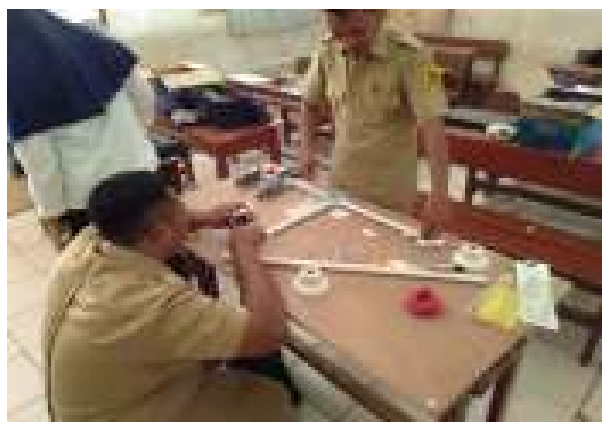

Gambar 4.11 Pemberian Pelatihan

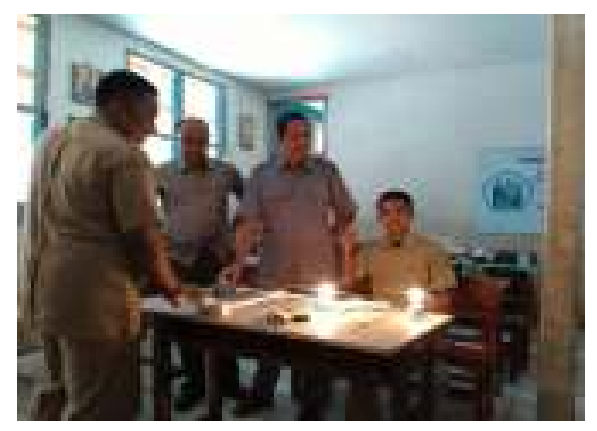

Gambar 4.12 Pemberian Pelatihan

\section{Hasil Kegiatan Pengabdian}

Kegiatan pengabdian masyarakat berbasis program studi Teknik Listrik, jurusan teknik elektro, Politeknik Negeri Jakarta yang dilakukan di Madrasah Ibtidaiyah Miftahul Ulum Kecamatan Klapa Nunggal Kabupaten Bogor telah selesai dilaksanakan dengan baik dengan hasil yang telah direncanakan dan penambahan bagian bagian tertentu untuk menyempurnakan hasil yang didapat.

\section{KESIMPULAN}

Kegiatan pelaksaan Pengabdian Masyarakat Program Studi Teknik Listrik, Jurusan Teknik Elektro, Politeknik Negeri Jakarta yang dilakukan di Madrasah Ibtidaiyah 
Miftahul Ulum di Desa Leuwi Karet, kecamatan Klapa Nunggal kabupaten bogor telah dilaksanakan dengan baik dengan kegiatan yaitu :

1. Membangun toilet untuk berwudhu siswa dan guru.

2. Penggantian pintu dan kusen Toilet kamar mandi.

3. Pengecatan dan pemasangan plafon atap

4. Menginstalasi ruang Toilet dengan kelengkapan kotak kontak dan fitting lampu.

5. Mengganti plafon atap dan mengecat plafon ruang kelas.

6. Memperbaiki dinding ruang kelas pengecatan dinding kelas.

7. Memberikan pelatihan energi listrik dangan trik dalam menghemat penggunaan energi listrik.

\section{DAFTAR PUSTAKA}

[ 1 ] Rosyid, Abdul. 2011. Presentasi kuliah Photo voltaic. Program pasca sarjana ISTN.

[ 2 ] Rahardjo, Irawan. Fitriana, Ira. Analisa Potensi Pembangkit Listrik Tenaga Surya di Indonesia. Strategi Penyediaan Listrik Nasional dalam Rangka Mengantisipasi Pemanfaatan PLTU Batubara Skala Kecil PLTN, dan Energi Terbarukan.

[ 3 ] Vitta-Q. 2011. Struktur dan Cara Kerja Lead Acid Battery Accu. www.vitta-q.com

[9] Sulaiman. 2011. “Pembangkit Listrik Tenaga Matahari “. Dosen Universitas Bina dharma.
[ 4 ] Ir. SardonoSarwito, Msc. Indra Ranu Kusuma, ST,Msc. Didik Setiawan. 2010. "Analisa Teknis dan Ekonomis Penerapan Sel Surya untuk Kebutuhan Penerangan Jembatan Suramadu, Jurusan Teknik Sistem Perkapalan, FTK-ITS

[ 5 ] Imam Sudrajat, Prio Wibowo, Aditia Nur Bakti. 2010. “ Pengujian Radiasi Elektomagnetik Uninterruptable Power Supply ( UPS ) berdasarkan Standar BS-SN 62040-2 “. Prosiding PPI Standarisasi.

[ 6 ] FVG Energy s.p.A, 2012. “ Manual For Installation Use and Maintenance of FVG EnergyPhotovoltaic Modules “ www.fvgenergy.com

[ 7 ] Arie Septia Yudha, Agung Warsito, Karnoto. " Perancangan Inverter jenis Push-Pulldan ON-OFF Battry Charge Regulator ( BCR ) Pada Aplikasi Photovoltaic Sebagai sumber Energi Untuk Pompa air atau Penerangan ". Jurusan Teknik Elektro, Universitas Diponegoro. 